\title{
First Report of Gloeosporidina sp. Isolated from Lesions on Shoots and Leaves of Eucalyptus nitens and E. globulus in Australia
}

Z. Q. Yuan, School of Agricultural Science, University of Tasmania, GPO Box 252-54, Hobart, Tasmania 7001, Australia, and CSIRO Forestry and Forest Products, Tasmanian Research Centre, GPO Box 252-12, Hobart, Tasmania 7001, Australia; T. Wardlaw, Forestry Tasmania, GPO Box 207B, Hobart, Tasmania 7001, Australia; and C. Mohammed, School of Agricultural Science, University of Tasmania, GPO Box 252-54, Hobart, Tasmania 7001, Australia, and CSIRO Forestry and Forest Products, Tasmanian Research Centre, GPO Box 252-12, Hobart, Tasmania 7001, Australia

\begin{abstract}
Yuan, Z. Q., Wardlaw, T., and Mohammed, C. 2000. First report of Gloeosporidina sp. isolated from lesions on shoots and leaves of Eucalyptus nitens and E. globulus in Australia. 84:510-512.

A mitosporic fungus with small conidia was frequently isolated from blighted shoots and leaves of young plantation trees and nursery seedlings of Eucalyptus nitens and E. globulus in Tasmania. Lesions on these shoots and leaves are purple to light brown, becoming necrotic with welldefined margins. The fungus is characterized by having acervular conidiomata, cylindrical to lageniform monophialidic conidiogenous cells, and spheroid to pyriform conidia that are hyaline, aseptate, and often produced in chains. The morphological characteristics fit the published description for the genus Gloeosporidina. This is the first record of a member in the genus from Australia and the first time a Gloeosporidina species has been found on eucalypts.
\end{abstract}

Health surveys of eucalypt plantations were carried out in August 1998 in northwestern Tasmania. A leaf and shoot blight was encountered for the first time in three 1-year-old plantations, one of Eucalyptus nitens (Deane \& Maiden) Maiden and two of E. globulus Labill. Affected trees occurred at a very low incidence (less than $0.1 \%$ ) and tended to be stunted with low vigor due to mammal browsing damage. In February 1999, several potted seedlings of E. nitens with similar, but more severe symptoms were found in a forest nursery at Perth in northern Tasmania.

Necrotic, purple to light brown, irregular (up to $6 \mathrm{~cm}$ long and $1 \mathrm{~cm}$ wide) lesions were found on these blighted shoots and leaves. Lesions on shoots were light brown, with distinct purple margins and some nearly girdled stems (Fig. 1A and B). Minute, black acervuli were observed on the diseased tissues of shoots (Fig. 1B). Lesions from leaves of plantation trees were distinct and narrow, developing along the middle vein, initially showing purple discoloration, becoming light brown and necrotic with well-defined purple margins (Fig. 1C). Leaf lesions of nursery plants were slightly different from those of plantation trees. Lesions were less regular, up

Corresponding author: Z. Q. Yuan

E-mail: Ziqing.Yuan@ffp.cisro.au

Accepted for publication 28 December 1999.

Publication no. D-2000-0313-04R

(C) 2000 The American Phytopathological Society to $5 \mathrm{~mm}$ diameter, often confluent, covering a leaf surface area of more than $50 \%$. No acervuli were observed on these infected leaves.

Isolations were made to determine the identity of the fungus associated with the disease. Morphological characteristics indicate that this fungus is a species in the genus Gloeosporidina, morphologically close to G. moravica Petr. (7) and G. platani Butin \& Kehr (1), and a description is given in this paper.

\section{MATERIALS AND METHODS}

One E. nitens nursery seedling with numerous leaf lesions was sampled from Forestry Tasmania's Nursery in Perth, northern Tasmania. Two 1-year-old seedlings with similar lesions on both shoots from a different plantation site in Smithton, northwest Tasmania. A 1-year-old seedling of E. globulus, also with similar leaf lesions, was sampled from a Smithton plantation.

Leaf lesions at two different stages of development, less-developed purplish lesions and older necrotic lesions, were examined. Four leaves were sampled per plant; two with young lesions and two with old lesions, nine fragments per leaf. In addition, tissue from the margins of lesions on two current-year shoots per seedling was excised and cut into nine small fragments per lesion.

Excised shoot and leaf fragments were rinsed with $95 \%$ ethanol and washed with sterile water, then surface-sterilized with $5 \%$ sodium hypochlorite for $2 \mathrm{~min}$ and and leaves were collected, each seedling rinsed with sterile water. The surface-sterilized fragments were placed onto $3 \%$ malt extract agar (MEA), incubated for 7 to 14 days at $21^{\circ} \mathrm{C}$ in darkness, and assessed for fungal colony development.

Acervuli from shoot lesions were examined microscopically using squash mounts and thin median sections in Shear's mounting fluid. Fifty mature conidia from both field collections (shoots) and cultures (on leaves after incubation and on agar) were measured, and means were determined.

\section{RESULTS}

A mitosporic fungus with small conidia was examined on the shoot lesions having acervuli. The same fungus was recovered from all shoot fragments cultured from the margins of the shoot lesions. All fragments from old necrotic leaf lesions of field and nursery plants also yielded this fungus. It was isolated from $44 \%$ of the leaf fragments sampled from the margins of young purple lesions. Acervuli were found producing on some of these young purplish leaf lesions after the leaves were incubated under moist conditions in petri dishes (Fig. 1D).

Colonies of the fungus on 3\% MEA were velvety with fine radiations, light gray initially, turning mouse gray or dark gray with age (Fig. 1G). Reverse of the colonies was yellow-brown or dark amber colored with dark brown to black margins (Fig. 1E and F). Fruiting bodies were produced on pure cultures 2 weeks after incubation in darkness.

Morphological examination of fieldcollected specimens and the fungal isolates indicated that collections of the fungus from eucalypt shoots and leaves were congeneric with $G$. moravica, the type species of the genus. A detailed description based on the eucalypt isolates is as follows:

Gloeosporidina sp. (Figs. 1H and 2A-C)

Caulicolous and foliicolous. Conidiomata acervular, more or less circular, 160 to $200 \mu \mathrm{m}$ in diameter, subcuticular, scattered, brown, composed of hyaline pseudoparenchymatous cells (approximately $2.5 \mu \mathrm{m}$ in diameter). Conidiogenous cells formed directly from the upper cells of the conidiomata, enteroblastic, monophialidic 
with a short collarette and a distinct phialidic channel surrounded by a thickened region of the conidiogenous cell wall, terminal, discrete, determinate, hyaline, cylindrical to lageniform, 5 to $8 \times 2.5$ to $3.5 \mu \mathrm{m}$. Conidia hyaline, aseptate, spheroid to pyriform, base more or less truncate, 2 to $3 \times 2 \mu \mathrm{m}$, produced in chains.

\section{DISCUSSION}

Gloeosporidina (5) is a genus of mitosporic fungi and currently contains four to five species (2). The genus produces subepidermal to epidermal acervuli with cylindrical enteroblastic conidiogenous cells and distinctive tiny, aseptate, hyaline conidia (6). The fungus, isolated from E. nitens and E. globulus in Tasmania, closely matches the original description of $G$. moravica in conidial morphology and size $(2.5$ to $3.5 \times 2 \mu \mathrm{m})(6,7)$, except for the presence of lageniform conidiogenous cells.

Butin and Kehr (1) reexamined both the original type material and fresh material of G. moravica collected from Quercus leaves and gave a slightly larger conidium size than the type description ( 3.2 to $4.2 \times 2.0$ to $2.4 \mu \mathrm{m})$. They proposed a new species, G. platani, with smaller subglobose conidia measuring 2.4 to $2.8 \times 2.2$ to $2.4 \mu \mathrm{m}$, found on dead leaves of Platanus $\times$ hispanica in Germany. This separation of $G$. platani and G. morovica was supported by Butin and Kehr (1) using random amplified polymorphic DNA markers. The fungus from Eucalyptus, characterized by a wide range of conidial size and shape, therefore resembles both $G$. platani and $G$. morovica.

Using random amplified polymorphic DNA markers, Butin and Kehr (1) identified $G$. platani as the spermatial state of Apiognomonia veneta, the fungus that causes sycamore anthracnose, and $G$. moravica as the spermatial state of $A$. quercina, the causal agent of oak anthracnose. Members of the genus Apiognomonia have not been previously recorded on any host plants from Australia. During this study, no teleomorph associated with Gloeosporidina sp. was observed on either plant material or cultures. Although the conidia differ in size from those of other
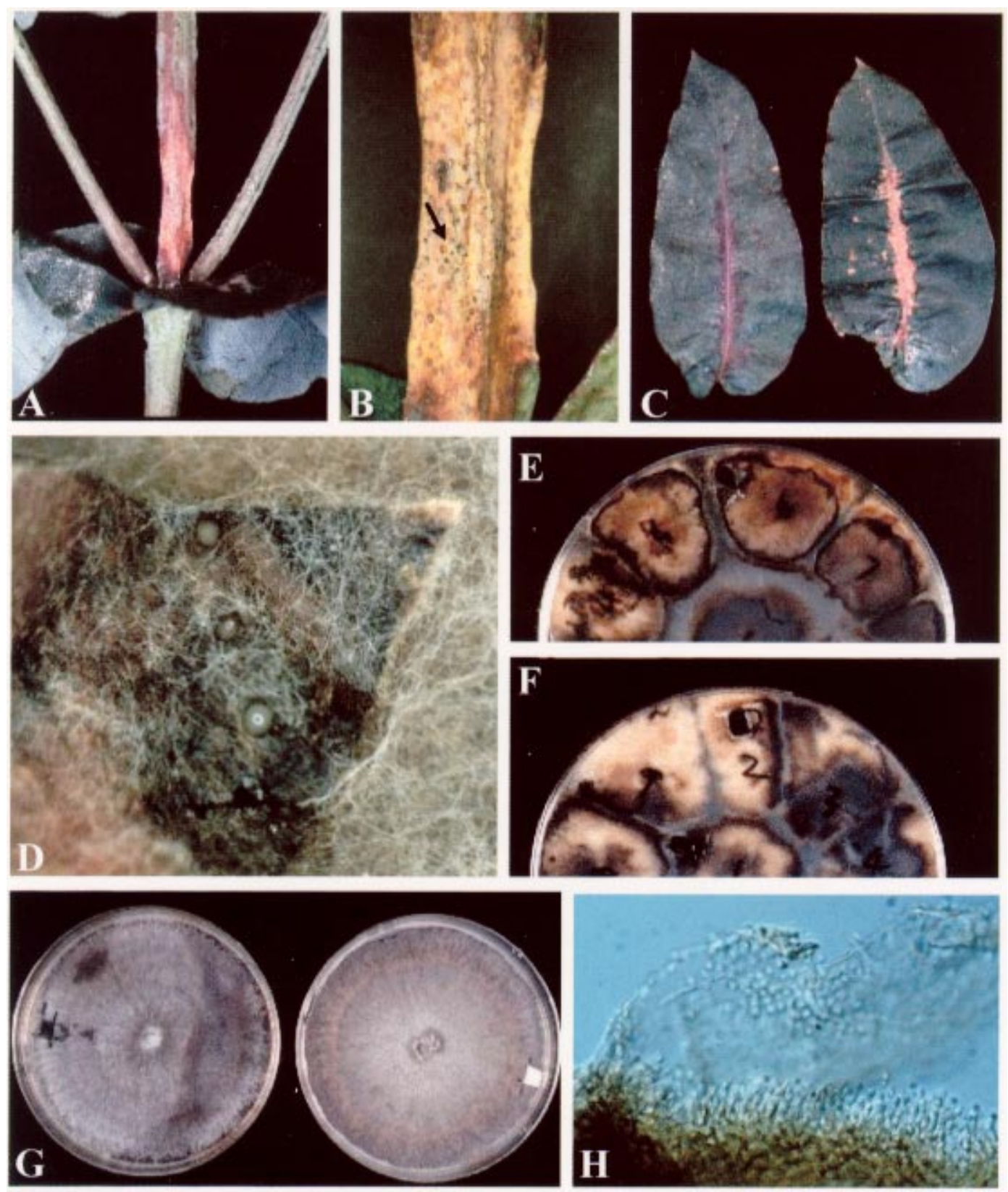

Fig. 1. Gloeosporidina sp. on 1-year-old Eucalyptus nitens: (A, B) on shoot, note black conidiomata on lesion area (arrow), (C) on leaves (left leaf: early stage with purple discoloration along vein, right leaf: late stage with light brown necrotic vein tissue), (D) sporulating on leaf fragment during incubation, (E) reverse view of colonies growing from shoot fragments, (F) reverse view of colonies growing from leaf fragments, (G) colonies on 3\% malt extract agar after 12-day incubation (left: from shoot lesion, right: from leaf lesion), (H) vertical section of acervulus (×600). 


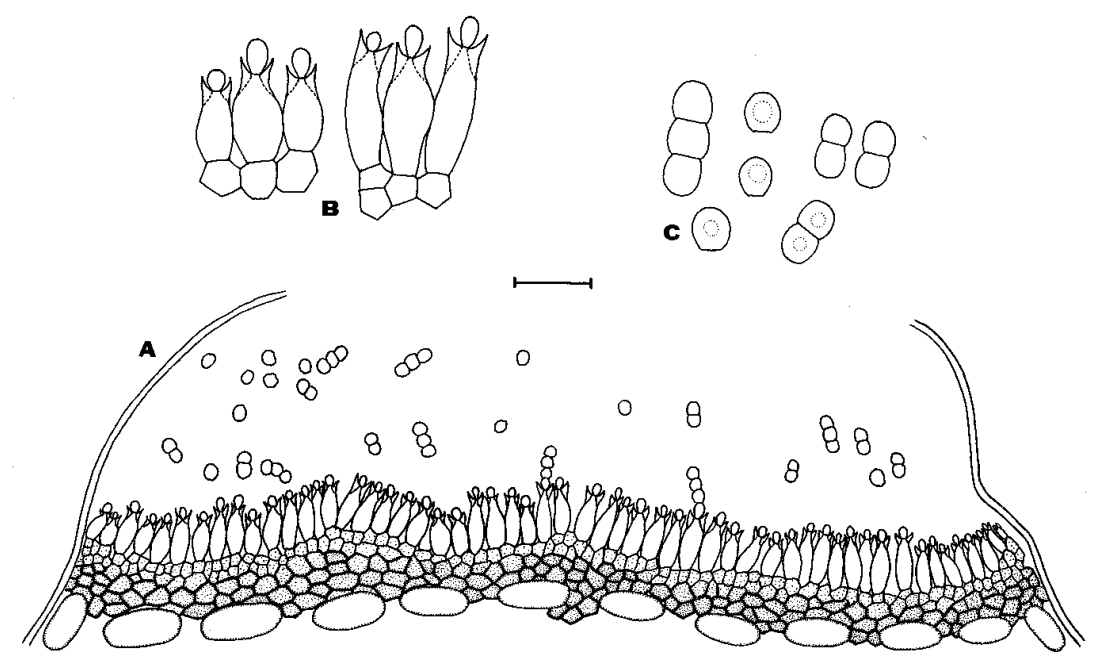

Fig. 2. Morphology of Gloeosporidina sp.: (A) vertical section of acervulus, (B) conidiogenous cells, (C) conidia. (Bar $=15 \mu \mathrm{m}$ for $\mathbf{A}$ and $5 \mu \mathrm{m}$ for $\mathbf{B}$ and $\mathbf{C}$ ).

Gloeosporidina species, the difference is slight. Without the observation of an associated teleomorph, further molecular and morphological studies will be required for species description.

Species of the genus Gloeosporidina are found on plant leaves and shoots, as well as on galls induced by other fungi (6). There have been two species reported in association with leaf lesions: G. cercocarpi on Cercocarpus betuloides in the United States and G. canthiicola on Canthium venosum in Zambia (6,7). Kubono (3) described $G$. cryptomeriae isolated from were infrequently encountered, and impact of the disease was minor. However, consistent isolation from distinct shoot and leaf lesions on young plantation trees and nursery seedlings indicates its potential as a causal agent of disease, and further pathogenicity tests using artificial inoculation of both young and old Eucalyptus are recommended.

\section{ACKNOWLEDGMENTS}

The senior author wishes to thank the Forest \& Wood Products Research \& Development Corporation (FWPRDC) for his postdoctoral fellowship.

\section{LITERATURE CITED}

1. Butin, H., and Kehr, R. 1998. Gloeosporidina platani sp. nov., the spermatial state of the anthracnose fungus Apiognomonia veneta (Sacc. \& Speg.) Hoehn. Eur. J. For. Pathol. 28:297305.

2. Hawksworth, D. L., Kirk, P. M., Sutton, B. C., and Pegler, D. N. 1995. Ainsworth and Bisby's Dictionary of the Fungi. CAB International, Egham, Surrey, England.

3. Kubono, T. 1993. Gloeosporidina cryptomeriae sp. nov. causing twig blight of Japanese cedar (Cryptomeria japonica). Trans. Mycol. Soc. Jpn. 34:261-265.

4. Kubono, T. 1994. Symptom development of the twig blight of Japanese cedar caused by Gloeosporidina cryptomeriae. J. Jpn. For. Soc. 76:52-58.

5. Petrak, F. 1921. Mykologische Notizen. III. Ann. Mycol. 19:176-223.

6. Sutton, B. C. 1980. The Coelomycetes. CAB International Mycological Institute, Kew, England.

7. Sutton, B. C., and Pollack, F. G. 1973. Gloeosporium cercocarpi and Sphaceloma cercocarpi. Mycologia 65:1125-1134. 